Proceedings

\title{
Contribution to the Evaluation of the Cultural Level of Hygiene and Industrial Safety at the Level of Algerian Cement Factories
}

\author{
Meriem Abdi ${ }^{1,}$ Rachid Chaib ${ }^{1}$ and Ion Verzea ${ }^{2}$ \\ 1 Laboratory of Transport Engineering and Environment, Mentouri University, Constantine1, Algeria; \\ rimelrimou14@gmail.com; rchaib@umc.edu.dz; \\ 2 Department of Engineering and Management, the "Gheorghe Asachi" Technical University of Iasi, Roma- \\ nia; ion.verzea@academic.tuias \\ * Correspondence: rimelrimou14@gmail.com
}

Publisher's Note: MDPI stays neutral with regard to jurisdictional claims in published maps and institutional affiliations.

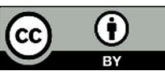

Copyright: $@ 2020$ by the authors. Submitted for possible open access publication under the terms and conditions of the Creative Commons Attribution (CC BY) license (http://creativecommons.org/licenses/by/4.0/).

\begin{abstract}
This work is an opportunity for assess the attitude and cultural level of cement plants in occupational health and safety then initiate a sustainable development strategy and engage in a continuous improvement process. Its objective is to provide strategic decision support for the management of the risks facing our cement factories while being based on knowledge of the attitude and the cultural level of employees in health and safety at work. This evaluation of the safety culture is a first step in the process towards its development. Such an initiative makes it possible to build a global and sustainable OHS strategy in order to avoid damage and losses while achieving their objectives, or even succeed in preventing accidents and occupational diseases. Our study is based on an in situ observation. It consists of a survey of cement factory employees to enable us to determine the elements to be improved in occupational health and safety, including with regard to the organizational and financial aspect of the latter. As a case study, we have chosen three cement factories in eastern Algeria.
\end{abstract}

Keywords: Occupational health and safety (OHS), cultural level; risk management; performance of cement factories and occupational hygiene

\section{Introduction}

It emerges from a study carried out in the Hamma Bouziane cement plant that a rational management of industrial health and safety is essential and becomes one of the essential conditions for compliance with hygiene rules, not only for employees, but also in the general environment [1]. Based on these results, we want through this work to assess the attitude and cultural level of some cement factories in eastern Algeria in occupational health and safety to then engage in a process of continuous improvement. This evaluation of the safety culture corresponds to a first step in the process towards its development. Such an initiative helps to prevent accidents and occupational diseases, thus avoiding serious consequences for workers and the company. Various publications and surveys have shown that current conditions of hygiene, health, safety and management are not always satisfactory for human health $[2,3,4,5,6]$.However, the recommended methods of management and management of occupational health and safety require significant technical, organizational and financial resources as well as a legal framework which is often lacking in reality $[7,8]$. Therefore to identify and supervise the risks and arrive at these organizational and hygienic attributes, a cultural level of the cement plant staff must be part of the elementary values of the actors of the world of work in this field. In this context, we try through this contribution to assess the attitude and the cultural level of the cement plant staff in risk management in order to promote risk management in our cement works and thus succeed in establishing and adapting the most appropriate techniques and measures: engaging in a continuous improvement process while relying on precise regulations. As 
a case study, we have chosen three cement factories in Eastern Algeria. Indeed, establishing an OHS culture consists in putting in place policies and directives that promote the values of employee well-being and workforce safety.

\section{Methodology of Work}

Various methods have been designed to study knowledge of the security situation and tend to understand and measure the progress of security behaviors with a view to establishing a lasting effective security culture in companies $[9,10]$. The qualitative assessment of the safety culture is generally based on the performance of interviews, observations, audits and documentary analysis to collect all the necessary information. Employees play a key role in encouraging the company to develop strategies to improve safety at work $[11,12,13]$.Therefore, our study is consists of a survey of employees at cement plants to determine what needs to be improved in occupational health and safety, including the organizational and financial aspects. It's based on an in situ observation. This survey is based on dependent variables and their indicators are linked to the assumptions and objectives of our work. The population of our study is made up of a set of personnel from different functions of the three cement factories in eastern Algeria. The sample size was determined using a sampling technique based on a recommended probability method [14]. Our sample is distributed as follows, Table 1.

Table 1. Actual distribution.

\begin{tabular}{ccccccc}
\hline Cement plant & \multicolumn{2}{c}{ Hamma Bouziane } & \multicolumn{2}{c}{ Hadjar sud } & \multicolumn{2}{c}{ Elma Labiod } \\
\hline Age range (years) & $\mathbf{N b}$ & $\mathbf{( \% )}$ & $\mathbf{N b}$ & $\mathbf{( \% )}$ & $\mathbf{N b}$ & $\mathbf{( \% )}$ \\
\hline $22-27$ & 12 & 17.39 & 14 & 14.29 & 14 & 16.29 \\
\hline $28-33$ & 18 & 26.09 & 24 & 24.49 & 20 & 22.99 \\
\hline $34-39$ & 18 & 26.09 & 23 & 23.47 & 19 & 21.84 \\
\hline $40-45$ & 18 & 26.09 & 25 & 25.51 & 20 & 22.99 \\
\hline $46-51$ & 7 & 10.15 & 8 & 8.16 & 8 & 9.20 \\
\hline $52-57$ & 5 & 7.25 & 4 & 4.08 & 6 & 6.90 \\
\hline
\end{tabular}

\section{Results and Discussions}

The analysis of the results of our survey is shown in the following figures:

\section{Cause 1: Lack of experience and motivation}

Finding: results show that the categorie most affected by this cause is the group (2227 , with more than $70 \%$, because of the the lack of experience and the low level of training and informations. However, for the oldest age group (46-51) with more than 50\%, this can be explained by the lack of motivation as they prepare for retirement.

Figure 1. Distribution according to lack of experience and motivation.

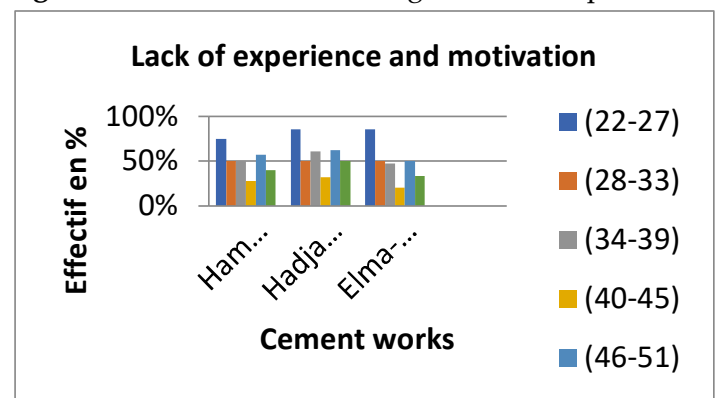

Cause 2: Difficult working conditions 
Finding: the categories of employees most concerned by this cause are the categories of (22-27) and (46-51), with more than 70\%, this is explained by the lack of experience for the first age category and by the weak reaction due to aging for the second age group. These two categories are related to each other, except that the first is linked to lack of experience and the second to lack of responsiveness.

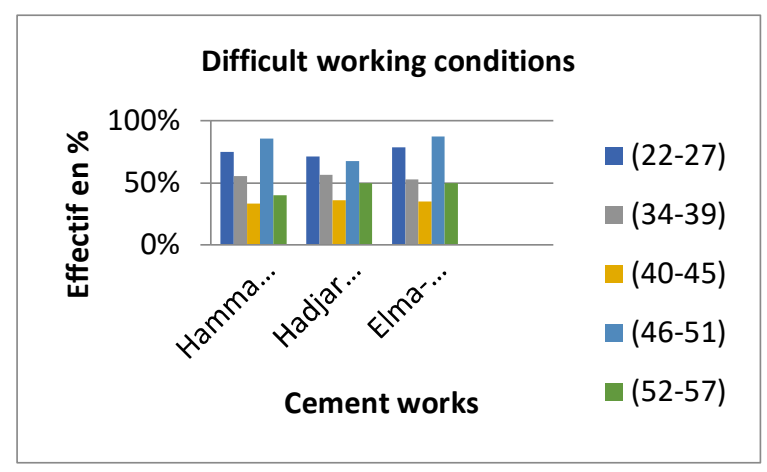

Figure 2: Distribution according to difficult working conditions.

\section{Cause 3: Insufficient machine safety}

Finding: here, the categories of employees (28-33) and (52-57) are the most affected by this cause with more than $80 \%$.In our opinion, this is explained for the category (2833) who have already acquired some experience and by their direct exposure to the different machines, because most are operators. However, for the second category, this is due to the different jobs occupied during their careers and repeated exposure to different machines.

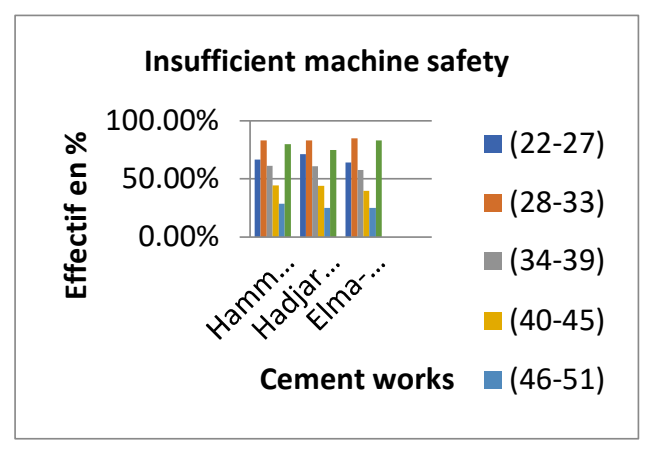

Figure 3. Distribution according to insufficient machine safety.

\section{Cause 4: Stress}

Finding: we note here that the category of young employees (22-27) and the category of older employees (46-51) and (52-57) are the most affected.with $80 \%$ and more than $70 \%$, This can be explained for the young employees that the latter recruited are not yet accustomed to their work and also the nature and the working conditions. However, for the other two categories, the more experienced suffer from stress due to very difficult working conditions, age and responsibility. 


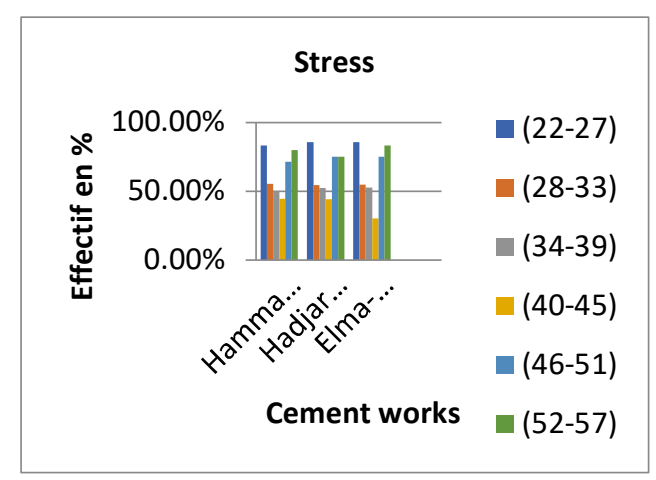

Figure 4. Distribution according to stress.

\section{Cause 5: Insufficient involvement of employees and management}

Finding: we can see according to the figure 5 that the categories of the most experienced workers who find that the causes of work accidents are due to insufficient involvement of employees and management, with more than $55 \%$. This can be explained by the lack of communication between the different hierarchical levels, the non-involvement of different categories in decision making.

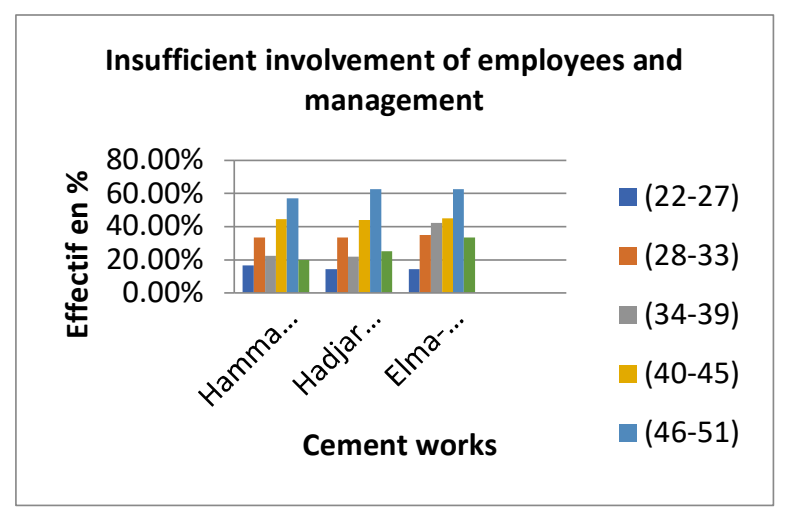

Figure 5. Breakdown according to insufficient involvement of employees and management.

\section{Cause 6: Presence of burn-in or presenteeism}

Finding: the graph shows that categories (28-33), (34-39) followed by the categories (46-51) and (52-57) attributed the cause of work accidents to burn-in or presenteeism. This can be explained by their knowledge of the importance of physical and mental well-being in the performance of assigned tasks at their workstations and how this syndrome can influence their performance. this difference in the responses is due to the task, the nature and the workstation occupied. 


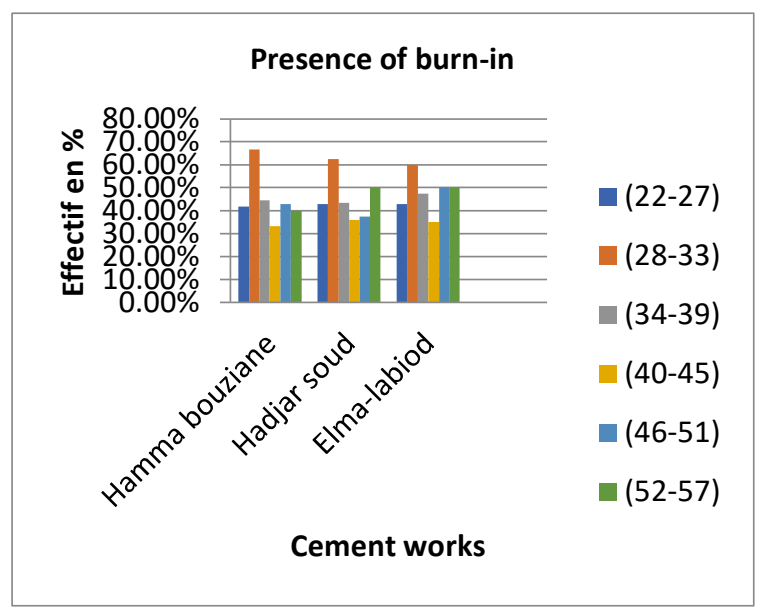

Figure 6. Distribution according to the presence of burn-in or presenteeism.

\section{Cause 7: Insufficient involvement of employees and management}

Finding: In the figure, we can see that the categories of the most experienced workers (46-51) with more than $60 \%$ who find that the causes of work accidents are due to insufficient involvement of employees and management. This can be explained by the lack of communication between the different hierarchical levels, the non-involvement of different categories in decision making.

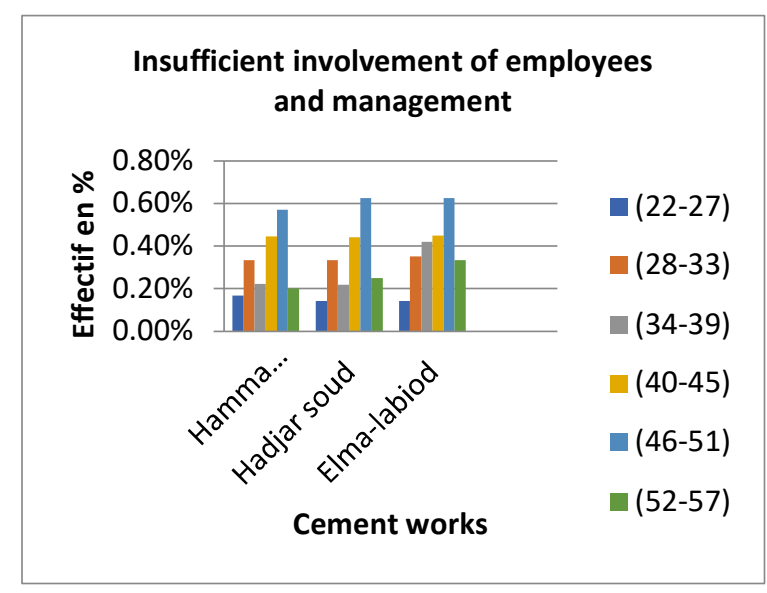

Figure 7. Breakdown according to insufficient involvement of employees and management.

\section{Cause 8: Other causes}

Finding: the graph clearly shows that it is experience that speaks. The category of age (46-51) with the highest percentage more than $40 \%$. In our opinion, these categories are the most experienced, they have in-depth knowledge of the site and the various existing problems and also they have experienced various work accidents during their career. 


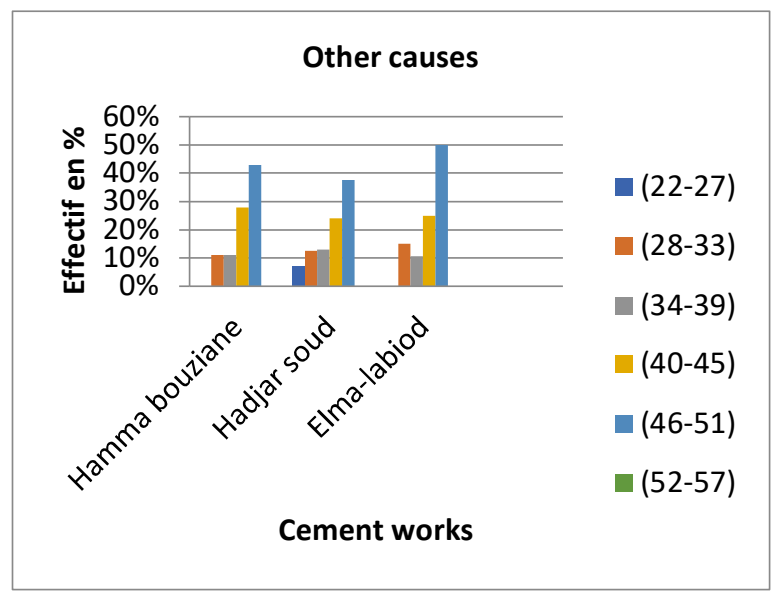

Figure 8. Distribution according to other causes.

\section{Conclusion and Recommendations}

According to the results obtained in this study, all the actions carried out so far have turned out to be faulty and disparate and the staff is often powerless to manage his health and safety without any training, information and orientation on risks incurred by the various activities. The result of the survey clearly shows that the three cement factories are at the same cultural level in health and safety at work, barely a few differences in the figures.

As a result of our investigation, it was seen that there is a:

- Lack of a comprehensive prevention approach;

- Insufficient OSH awareness among employees and management;

- Lack of knowledge of OSH regulations;

- A considerable lack in communication and ethical reflection.

- Lack of experience and means of motivation.

As a result, and following our work results, in order to help OHS managers at the study cement factories and Algerian cement factories in general to reduce work accidents while improving the safety culture, which leads to improving performance in this area and competitiveness on the market, we offer all of the following recommendations based on the general principles and best practices for preventing occupational risks:

- Promote, enhance, inform and train in OSH;

- Call on feedback. They can serve as a basis for undertaking future preventive actions;

- Develop training and welcome programs for new hires, as well as continuing training for employees, without forgetting social dialogue (with employee representatives),

- $\quad$ harmonize the health and safety policy with other company policies;

- promote a multi disciplinary approach (technical, human and organizational)

- $\quad$ Analyze work accidents and occupational diseases by going back to the most upstream causes

\section{References}

1. Chaib ,R;Verzea, I; Cozminca ,I; Benidir ,M.Preserving and Improving the Safety and Health at Work: Case of Hamma Bouziane Cement Plant (Algeria), Safety Science 2015, Volume 76, Pages 145-150, Science Direct, Elsevier.

2. Badri, A; André, G; and Sylvie, N.Occupational health and safety risks: Towards the integration into project management.Safety science 2012, 50.2 190-198. 
3. Dixon-Woods, M; Baker, R; Charles, K; et al. Culture and behavior in the English National Health Service: overview of lessons from a large multimethod study. BMJ quality \& safety, 2014, vol. 23, no 2, p. 106-115.

4. Oakden, J.P. The application of complexity theory to contracting out public health interventions: a thesis presented in fulfillment of the requirements for the degree of Master of Philosophy, School of Health at Massey University, Wellington, New Zealand. Doctoral thesis. Massey University. 2019.

5. Carney, G.R (2019), Motivation and Burnout amongst Millenials: An investigation into whether these factors differ amongst permanent employees and contingent employees. A Qualitative Study. Doctoral thesis. Dublin, National College of Ireland.

6. Inter-Organizational for the Sound Management of Chemicals (IOMC); Guidelines for establishing national waste management strategies: Moving from Challenges to Opportunities; ISBN: 978-92-807-3357-0; United Nations Environment Program, 2013.

7. JAIN, P; Pasman, H.J; Waldram, S, et al. Process Resilience Analysis Framework (PRAF): A systems approach for improved risk and safety management. Journal of LPPI 2018, vol. 53, p. 61-73.

8. Manu, P.M; Abdul-Majeed, N; Thuan, T et al .Health and safety management practices of contractors in South East Asia: A multi country study of Cambodia, Vietnam, and Malaysia. Safety science 2018, vol. 107, p. 188-201.

9. Ewerlöf, S; Modig, D. Value Creation and Decreased Environmental Impact through Circular Economy-based Offerings: A Product-Service System Case Study. 2019.

10. Abdul, Q; Bonaventura, HW; Hadikusumo. Multilevel safety culture affecting organization safety performance: a system dynamic approach, Engineering, Construction and Architectural Management 2019 , Vol. 26 No. 10, pp. 2326-2346, Emerald Publishing.

11. Guldenmund, F. "(Mis) understanding safety culture and its Relationship to safety management", Risk Analysis, Vol. 30 No. 10, pp. 1466-1480, available at: https://doi.org/10.11 11/ j.1539-6924.2010.01452.x

12. Ruiju, $\mathrm{Y}$;Wei ,Z ; Dora, M;Jiuchang ,W. Time to take corporate Innovation initiatives The consequence of safety accidents in China's manufacturing industry, Career Development International Vol. 24 No. 5, 2019 pp. 404-419, Emerald Publishing.

13. Chevreau, F;Wybo. JL.Practical approach to safety culture. For a more effective control of industrial risks, Review FG 2007, $\mathrm{n}^{\circ} 1742007 / 5,171-190$.

14. Survey techniques, DEGS faculty, University of Antananarivo, Madagascar. 